\title{
Teachers and clinical students' perception of the core competencies of different subjects of the undergraduate BDS curriculum
}

\author{
Dr. Md. Rasel Ahmad', Professor Dr. Iffat Ara', Professor Dr. Md. Humayun Kabir Talukder, \\ Brig Gen (Dr) Dipak Kumer Paul Chowdhury ${ }^{4}$, Dr. Md. Immam Hossin ${ }^{5}$, Dr. Md. Mahafuzur Raihan ${ }^{6}$
}

\section{Abstract}

Background: Curriculum planning and designing is not a static process, rather a continuous process done regularly through a system. More than one decade have elapsed since the Centre for Medical Education (CME), in 1988, developed a national Undergraduate Dental Curriculum which was supposed to be community-oriented and competency based. The curriculum was partially implemented with the advancement of dental health science and application of newer techniques in dental practices in developed and developing countries.

Rationale: Competency is the ability to combine evidence based knowledge, personal attitudes, and clinical skills to undertake holistic dental care. Personal attributes may include creativity, ethics, aesthetics, and critical sense and personal attributes include a desire for patient wellbeing and to self-evaluate the effectiveness of the treatment. As life-long learning becomes a crucial attribute for all modern clinicians, the ability to self-assess performance and identify future learning goals is an essential skill that needs to be developed in a modern healthcare curriculum. Self-assessment, self-reflection and selfregulation can promote a deeper understanding in current knowledge. The essential professional clinical skills may include a) diagnosis and treatment planning b) Preventative measures c) patient treatment and rehabilitation. Other skills that may be essential include professionalism, administrative and promotional skills. It is important that universities and dental schools help students nurture these values from a very early stage.

Objectives: The present study was undertaken to identify the teachers and clinical students' perception of the core competencies of different subjects of the undergraduate BDS curriculum.

Methods: This descriptive type of cross sectional study was conducted in seven public and private dental colleges of Bangladesh after getting written permission from the principal of the respective dental colleges. Voluntary participation of the students was ensured and the names of the students' as well as teachers were kept confidential. The teachers and students of final years from the different dental colleges were the study population; among them four hundred (400) students and one hundred twenty teachers (120) were taken as sample by convenient sampling. Data collection instrument was a semistructured questionnaire with 5-point Likert scale for final year students' and in depth interview was used for teachers. Results: The study revaled that $95 \%$ mentioned that introduction part of the curriculum competency in relation to the knowledge, skills and attitude of a dental graduate must be mentioned. Nearly 97 of the students mentioned that competency acquired by the newly passed dental graduate from the BDS course was satisfactory.

Conclusion: Competency-based dental education is a continuous process in maintaining a degree of quality consistent with patient well-being and effective treatment management path, which the graduating dentist should achieve. The cultural and socioeconomic diversity among different communities might have an impact on the profile of the professional needed by the society.

Key Words: Teachers perceptions, Clinical Students, Core Competences, Clinical skills, Students' perceptions, BDS curriculum.

\section{Introduction}

Competency-based dental education has been with us for more than a decade. It appears to have established itself as a

\footnotetext{
${ }^{1}$ Dental surgeon \& Medical Educationist

${ }^{2}$ Professor Department of Gynecology and Obstetrics.

${ }^{3}$ Professor, Curriculum Development \& Evaluation

Centre for Medical Education (CME), Mohakhali, Dhaka.

Professor \& Head, Department of Pharmacology \& Therapeutics Armed Forces Medical College, Dhaka

${ }^{4}$ Dental surgeon, Department of Oral and Maxillofacial Surgery Dhaka Dental College Hospital

${ }^{5}$ Associate Professor and Head, Department of Oral Anatomy Saphena Women's Dental College, Dhaka
}

Address of correspondence: Dr. Md. Rasel Ahmad, Dental Surgeon E-mail: raselbds42@gmail.com regular feature of discussions about curriculum management and clinical evaluation; it is also a required element in accreditation ${ }^{1}$. As used in this document, a "competency" is a complex behavior or ability essential for the general dentist to begin independent, unsupervised dental practice. Competence includes knowledge, experience, critical thinking and problem-solving skills, professionalism, ethical values, and technical and procedural skills ${ }^{2}$. These components become an integrated whole during the delivery of patient care by the competent general dentist. Competence assumes that all behaviors are performed with a degree of quality consistent with patient well-being and that the general dentist can self-evaluate treatment effectiveness. In competency-based dental education, what students learn is based upon clearly articulated competencies and further assumes that all

Bangladesh Journal of Medical Education 2017;8(2):24-28. (C) 2017 Ahmad et al., publisher and licensee Association for Medical Education. This is an Open Access article which permits unrestricted non-commercial use, provided the original work is properly cited. 
behaviors/abilities are supported by foundation knowledge and psychomotor skills in biomedical, behavioral, ethical, clinical dental science, and informatics areas that are essential for independent and unsupervised performance as an entry-level general dentist ${ }^{3}$. In creating curricula, dental faculty must consider the competencies to be developed through the educational process, the learning experiences that will lead to the development of these competencies, and ways to assess or measure the attainment of competencies. Undergraduate dental education should enable the learner to manage and treat a patient holistically while discipline-based education has tended to be more focused on a particular discipline often predispose students to mechanical role. Guidance to the curriculum development should be based on preparing a student to holistically manage and treat a patient; this should involve assessment of the learners' professional skills, interpersonal and research skills. The curriculum should motivate learners to acquire knowledge, enable them to self-assess and work in a team. This should reduce the focus on a teacher-dependent learning system and promote self-directed learning. As learners move beyond formal education and mature toward mastery in their professions, they should assume responsibility for directing their own professional development. Kaufman categorized curriculum as the transmission of knowledge, learning experience/process, and outcomes. He stated that learners must have the opportunity to develop professional skills that directly improve or attain the expected outcome leading to patient satisfaction and improved health. These skills include asking questions, critically appraising new information, identifying their own knowledge and skill gaps ${ }^{4}$.

\section{Methodology}

This descriptive type of cross sectional study was conducted in seven public and private dental colleges of Bangladesh after getting written permission from the principal of the respective dental colleges. Voluntary participation of the students was ensured and the names of the students' as well as teachers were kept confidential. The teachers and students of final years from the different dental colleges were the study population; among them four hundred (400) students and one hundred twenty teachers (120) were taken as sample by convenient sampling. Data collection instrument was a selfadministered semi structured questionnaire with 5-point Likert scale for final year students' a self-administered semi structured questionnaire was used for the dental teachers and in depth interview was used for teachers. The researcher himself visited selected dental colleges. He was introduced himself to the principal of the dental colleges, course coordinators and the teachers of all departments to conduct the study. The investigator himself collected all the data with prior permission of the principles and heads of the concerned departments. The semi-structured questionnaire was prepared on the basis of variables of the study. The respondents who wish to spent sufficient time were interviewed in-depth interview. All the collected data were checked manually. Data entry, editing, processing and analysis were done by using 19 version of SPSS compute software programme. Interpretations were done subsequently. Data were presented by tables and graphs with necessary description where necessary for easy understanding and interpretation. Results of in-depth interviews were presented by qualitative descriptions. Necessary permissions were taken from all the concerned authorities to conduct the study.

\section{Results}

Table 1shows out of 97 teachers most of them 95(97.9) mentioned that introduction part of the curriculum competency in relation to the knowledge, skills and attitude of a dental graduate must be mentioned and 2(2.1) mentioned that introduction part of the curriculum competency in relation to the knowledge, skills and attitude of a dental graduate must not be mentioned.

Table 1: Distribution of the teachers by their opinion regarding the competences of a dental graduate

\begin{tabular}{|l|c|c|c|}
\hline \multirow{2}{*}{ Competences of a dental graduate } & \multicolumn{2}{|c|}{ Frequency (\%) } & \multirow{2}{*}{ Total } \\
\cline { 2 - 3 } & Yes & No & \\
\hline $\begin{array}{l}\text { Competency in relation to the } \\
\text { knowledge of a dental graduate } \\
\text { must be mentioned in the } \\
\text { introductory part of the curriculum }\end{array}$ & $95(97.9)$ & $2(2.1)$ & 97 \\
\hline $\begin{array}{l}\text { Competency in relation to the } \\
\text { attitudes of a dental graduate must } \\
\text { be mentioned in the introductory } \\
\text { part of the curriculum }\end{array}$ & $97(100)$ & - & 97 \\
\hline $\begin{array}{l}\text { Competency in relation to the skills } \\
\text { of a dental graduate must be } \\
\text { mentioned in the introductory part } \\
\text { of the curriculum }\end{array}$ & $95(97.9)$ & $2(2.1)$ & 97 \\
\hline
\end{tabular}

Table 2 shows out of 97 teachers majority 75(77.3) mentioned moderately competent, 20(20.6) average and 2(2.1) highly competent to the competences acquired by the dental graduate from the present curriculum was adequate for providing service to the country people.

Table 2: Distribution of the teachers by their opinion regarding level of competences acquired by the dental graduate from the present curriculum for providing service to the country people

\begin{tabular}{|l|l|l|}
\hline $\begin{array}{l}\text { Opinion about the competences acquired } \\
\text { by the dental graduate from the present } \\
\text { curriculum for providing service to the } \\
\text { country people }\end{array}$ & Frequency & Percent \\
\hline Highly competent & & \\
\hline Moderately competent & & \\
\hline Average & & \\
\hline Total & & \\
\hline
\end{tabular}

Table 3 shows different level of core competencies, out of 400 students 206(51.5) mentioned very satisfied, 182(45.5) satisfied in scope of proper history taking and recording. 288(72) mentioned satisfied in scope of proposing investigation to the patients. Out of 398 students 272(68.3) mentioned that they were satisfied and 2(.5) very dissatisfied

Bangladesh Journal of Medical Education 2017;8(2):24-28. 
in scope of counseling to the patient or attendants and 272(68.3) satisfied in scope of making diagnosis. Out of 398 students 346(86.9) mentioned that they were satisfied and few 2(.5) very dissatisfied in dealing with dental emergencies e.g. (faint, syncope, acute hypoglycemia etc.)

$(\mathbf{V D}=$ Very dissatisfied, $\mathbf{D}=$ Dissatisfied, $\mathbf{N S N D}=$ neither satisfied nor dissatisfied, $\mathbf{S}=$ Satisfied, $\mathbf{V S}=$ Very satisfied)

Table 3: Distribution of the students by their opinion regarding the general competencies $(n=400)$

\begin{tabular}{|l|c|c|c|c|c|c|}
\hline \multirow{2}{*}{ Statement in relation to clinical competencies } & \multicolumn{4}{|c|}{ Frequency No (\%) } & \multirow{2}{*}{ Total } \\
\cline { 2 - 6 } & VD (1) & D (2) & NSND (3) & S (4) & VS (5) & \\
\hline Scope of proper history taking and recording & $2(.5)$ & $3(.8)$ & $7(1.8)$ & $182(45.5)$ & $206(51.5)$ & 400 \\
\hline Scope of proposing investigation to the patients & - & $6(1.5)$ & $31(7.8)$ & $288(72)$ & $75(18.8)$ & 400 \\
\hline Scope of counseling the patient or attendants & $2(.5)$ & - & $58(14.6)$ & $272(68.3)$ & $66(16.6)$ & 398 \\
\hline Scope of making diagnosis & $2(.5)$ & - & $58(14.6)$ & $272(68.3)$ & $66(16.6)$ & 398 \\
\hline Scope of writing prescription & $2(.5)$ & - & $20(5)$ & $253(63.6)$ & $123(30.8)$ & 398 \\
\hline $\begin{array}{l}\text { Dealing with dental emergencies e.g. (faint, syncope, acute } \\
\text { hypoglycemia etc.) }\end{array}$ & $2(.5)$ & - & $24(6)$ & $346(86.9)$ & $26(6.5)$ & 398 \\
\hline $\begin{array}{l}\text { Scope of interpretation of investigation and records (e.g. X- } \\
\text { ray, OPG finding etc.) }\end{array}$ & $2(.5)$ & $9(2.3)$ & $140(35)$ & $168(42.4)$ & $77(19.4)$ & 396 \\
\hline Scope of performing local anaesthesia & - & $6(1.5)$ & $31(7.8)$ & $288(72)$ & $75(18.8)$ & 400 \\
\hline Scope of intraoral examining the patients & $2(.5)$ & $1(.3)$ & $13(3.3)$ & $212(53.4)$ & $169(42.6)$ & 397 \\
\hline Scope of relevant discussion with the supervisor & $7(1.8)$ & - & $95(23.9)$ & $205(51.5)$ & $91(22.9)$ & 398 \\
\hline
\end{tabular}

Table 4: Distribution of the students by their opinion regarding the clinical competencies $(n=400)$

\begin{tabular}{|l|c|c|c|c|c|c|}
\hline \multirow{2}{*}{ Statement in relation to clinical competencies } & \multicolumn{4}{|c|}{ Frequency No (\%) } & Total \\
\cline { 2 - 6 } & VD (1) & D (2) & NSND (3) & S (4) & VS (5) & \\
\hline Performing scaling & - & - & $3(.8)$ & $133(33.4)$ & $262(65.8)$ & 398 \\
\hline Performing operculectomy & - & $5(1.3)$ & $12(3)$ & $182(45.8)$ & $198(49.9)$ & 397 \\
\hline Performing gingivectomy & - & - & $69(17.3)$ & $289(72.6)$ & $40(10.1)$ & 398 \\
\hline Performing scaling periodontal pocket curettage & - & - & $69(17.3)$ & $289(72.6)$ & $40(10.1)$ & 398 \\
\hline Performing pulpotomy & - & - & $23(5.8)$ & $286(72.2)$ & $87(22)$ & 396 \\
\hline Performing pulpectomy & - & - & $74(18.6)$ & $209(52.5)$ & $115(28.9)$ & 398 \\
\hline Performing deciduous tooth restoration & - & $15(3.8)$ & $50(12.6)$ & $160(40.3)$ & $172(43.3)$ & 397 \\
\hline Performing deciduous tooth extraction & - & $24(6.1)$ & $34(8.7)$ & $163(40.8)$ & $172(43.8)$ & 393 \\
\hline Taking impression & - & $6(1.5)$ & $59(14.8)$ & $297(74.6)$ & $36(9)$ & 398 \\
\hline Constructing partial denture & 4 & $20(5)$ & $174(43.5)$ & $177(44.5)$ & $27(6.8)$ & 398 \\
\hline Constructing complete denture & $(1)$ & $158(39.5)$ & $97(24.7)$ & $121(30.8)$ & $13(3.3)$ & 393 \\
\hline Preparing tooth for metal ceramic crown & $48(12)$ & $148(37)$ & $90(22.5)$ & $87(21.8)$ & $27(6.8)$ & 400 \\
\hline Constructing removable appliance & $1(.3)$ & $24(6.1)$ & $59(15.1)$ & $257(65.6)$ & $51(13)$ & 392 \\
\hline Orthodontic diagnosis and treatment planning & $2(.5)$ & $27(6.8)$ & $36(9.1)$ & $239(60.5)$ & $91(23)$ & 395 \\
\hline $\begin{array}{l}\text { Treatment of different malocclusions using removable } \\
\text { appliance }\end{array}$ & - & $11(2.8)$ & $21(5.3)$ & $300(75.6)$ & $65(16.4)$ & 397 \\
\hline Preparing class 1, class 2, class 3, class 4 and class 5 cavities & - & $3(.8)$ & $105(26.4)$ & $263(66.2)$ & $26(6.5)$ & 397 \\
\hline Restoring class 1, class2, class 3, class 4 and class 5 cavities & $2(.5)$ & $4(1)$ & $87(21.9)$ & $269(67.3)$ & $35(8.8)$ & 397 \\
\hline $\begin{array}{l}\text { Performing root canal treatment (RCT) of anterior and } \\
\text { posterior teeth }\end{array}$ & - & $4(1)$ & $49(12.3)$ & $244(61.5)$ & $100(25.2)$ & 397 \\
\hline Performing extraction of anterior and posterior teeth & - & - & $16(4)$ & $269(67.8)$ & $112(28.2$ & 397 \\
\hline Performing minor surgery cysts, tumors, apisectomy etc. & - & $32(8.1)$ & $66(16.7)$ & $234(59.1)$ & $64(16)$ & 396 \\
\hline
\end{tabular}

Bangladesh Journal of Medical Education 2017;8(2):24-28. 
Table 4 shows out of 398 students majority 262(65.8) mentioned very satisfied and 3(.8) neither satisfied nor dissatisfied in performing of scaling and 198(49.9) mentioned very satisfied in performing of operculectomy and 289(72.6) mentioned satisfied in performing gingivectomy. Majority 289(72.6) mentioned satisfied and 69(17.3) neither satisfied nor dissatisfied in performing scaling and periodontal pocket curettage and 286(72.2) mentioned satisfied in performing pulpotomy. Out of 398 students majority 209(52.5) mentioned satisfied in performing of pulpectomy and 15(3.8) dissatisfied in performing deciduous tooth restoration and 297(74.6) mentioned satisfied in performing taking impression. On the other hand majority 177(44.5) mentioned satisfied 174(43.5) neither satisfied nor dissatisfied in constructing partial denture and 158(39.5) mentioned dissatisfied in constructing complete denture. Out of 397 students majority 300(75.6) mentioned satisfied in treatment of different malocclusions using removable appliance and 263(66.2) mentioned satisfied in preparing class 1 , class 2, class 3, class 4 and class 5 cavities and 244(61.5) mentioned satisfied in performing root canal treatment (RCT) of anterior and posterior teeth.

(VD=Very dissatisfied, $\mathbf{D}=$ Dissatisfied, $\mathbf{N S N D}=$ neither satisfied nor dissatisfied, $\mathbf{S}=$ Satisfied, $\mathbf{V S}=$ Very satisfied)

\section{Discussion}

Out of 97 teachers most of them 95(97.9) mentioned that introduction part of the curriculum competency in relation to the knowledge, skills and attitude of a dental graduate must be mentioned and 2(2.1) mentioned that introduction part of the curriculum competency in relation to the knowledge, skills and attitude of a dental graduate must not be mentioned.(Table 1). Out of 400 students 206(51.5) mentioned very satisfied, 182(45.5) satisfied in scope of proper history taking and recording. 288(72) mentioned satisfied in scope of proposing investigation to the patients. Out of 398 students 272(68.3) mentioned that they were satisfied and 2(.5) very dissatisfied in scope of counseling to the patient or attendants and 272(68.3) satisfied in scope of making diagnosis. Out of 398 students 346(86.9) mentioned that they were satisfied and few 2(.5) very dissatisfied in dealing with dental emergencies e.g. (faint, syncope, acute hypoglycemia etc.) (Table 3). Out of 398 students majority 262(65.8) mentioned very satisfied and 3(.8) neither satisfied nor dissatisfied in performing of scaling and 198(49.9) mentioned very satisfied in performing of operculectomy and 289(72.6) mentioned satisfied in performing gingivectomy. Majority 289(72.6) mentioned satisfied and 69(17.3) neither satisfied nor dissatisfied in performing scaling and periodontal pocket curettage and 286(72.2) mentioned satisfied in performing pulpotomy. Out of 398 students majority 209(52.5) mentioned satisfied in performing of pulpectomy and 15(3.8) dissatisfied in performing deciduous tooth restoration and 297(74.6) mentioned satisfied in performing taking impression. On the other hand majority 177(44.5) mentioned satisfied 174(43.5) neither satisfied nor dissatisfied in constructing partial denture and 158(39.5) mentioned dissatisfied in constructing complete denture. Out of 397 students majority 300(75.6) mentioned satisfied in treatment of different malocclusions using removable appliance and 263(66.2) mentioned satisfied in preparing class 1 , class 2 , class 3 , class 4 and class 5 cavities and 244(61.5) mentioned satisfied in performing root canal treatment (RCT) of anterior and posterior teeth (Table 4). A study conducted by Fazel, et al (2008) ${ }^{5}$ in which that out of 300 questionnaires distributed in the 30 provinces of the country, 250 questionnaires (83\%) were returned. While most of the participants considered the competencies as necessary for an Iranian dentist, less than $40 \%$ of the respondents believed that the graduates acquire the most required competencies of the profession during the current educational program. A study conducted by Licari et. al. $(2008)^{6}$ in which Fewer than half (46 percent) of the respondents were able to identify the conventional definition of competency that was stated as "a set of skills, knowledge, and values that characterize beginning dentists." Almost a quarter each identified "competency" as a type of clinical examination format ( 26 percent) or roughly the same as a clinical discipline (25 percent). Nine percent associated the primary meaning of "competency" as an accreditation requirement. A study conducted by Gerrow et. al. $(2006)^{7}$. The survey asked participants to supply demographic information and rate each of the forty-six competencies on a 5-point Likert scale. The response rate was 43.1 percent ( 315 total usable responses). Self-reported demographic data was used to create respondent subgroups. The participants rated all of the competencies quite high with thirty-six of the forty-six receiving rankings averaging 4.0 or higher on the 5-point scale. No competency received a ranking averaging lower than 3.0. A study conducted by Willis et. al. (2009) ${ }^{8}$. The ADEA Competencies for the New General Dentist contain a significant number of practice management-related competencies. To date, these have been taught primarily in a lecture format in the third and fourth years of the dental curriculum. Presenting information in this way only satisfies the lower level learning skills, not the skills needed to become a competent general dentist. A study conducted by Albino et. al.(2009) ${ }^{9}$ survey of assessment practices in predoctoral education was completed by 931 course directors, representing 45 percent of course directors nationwide, from fifty-three of the fifty-six U.S. dental schools. Survey findings indicate that five traditional mainstays of student performance evaluationmultiplechoice testing, lab practicals, daily grades, clinical competency exams, and procedural requirementsstill comprise the primary assessment tools in dental education. The survey revealed that a group of newer assessment techniques, although frequently identified as best practices in the literature and commonly used in other areas of health professions education, are rarely employed in predoctoral dental education.

Overall content coverage in the SAQ papers of the universities professional examination was satisfactory. But in case of coverage of different type of questions was not as

Bangladesh Journal of Medical Education 2017;8(2):24-28. 
per curriculum standard. Coverage of problem solving type question was negligible. Measures must be taken during moderation of university professional question papers to cover stated standard of different type questions in the curriculum.

\section{Conclusion}

In embracing a competency-based model for dental education, we must also incorporate into the curriculum evaluation strategies and assessment methodologies that will ensure the achievement of our ultimate goal: the education of competent general dentists.

\section{References}

1. 'ADEA Competencies for the New General Dentist' 2011, Journal of Dent Education; Vol. 75, No.7, pp.932935.

2. BM \& DC curriculum 2007.

3. Manakil J, George R, 2011, 'Reviewing Competency in Dental Education', International Journal of Dental Clinic; Vol.3, no.2, pp.33-39.

4. Rabbi G, Faruque M, et al. 2011, 'New dental graduates Satisfaction regarding acquired competencies during BDS course', Bangladesh Journal of Medical Education, Vol.- 02, Issue.-02, pp.26-31.

5. Fazel A, Jafari A, Khami MR, et al. 2001, 'Dental Curriculum Revision in Iran: Dentists' Perspective on Achievement of Essential Competencies through National Curriculum', Beheshti Univ Dent J. Vol.18, No.4,pp. 140.
6. Frank W. Licari, D.D.S.; David W. Chambers, Ed.M., M.B.A., Ph.D. "Some Paradoxes in Competency-Based Dental Education" Journal of Dental Education, Vol.72, Num.1, pp-1-18.

7. Jack D. Gerrow, D.D.S., M.S., M.Ed.; H. Joseph Murphy, Ed.D.; Marcia A. Boyd, D.D.S., M.A., L.H.D. (Hon). "Competencies for the Beginning Dental Practitioner in Canada: A Validity Survey" Journal of Dental Education. Vol.70, Num.10, pp.1076-1080.

8. David O. Willis, D.M.D., M.B.A., C.F.P. "Using Competencies to Improve Dental Practice Management Education". Journal of Dental Education. Vol.73, Num.10,pp-1144-1152.

9. Judith E.N. Albino, Ph.D.; Stephen K. Young, D.D.S.; Laura M. Neumann, D.D.S., M.P.H.; Gene A. Kramer, Ph.D.; Sandra C. Andrieu, Ph.D.; Lindsey Henson, M.D.; Bruce Horn, D.D.S.; William D. Hendricson, M.S., M.A. “Assessing Dental Students' Competence: Best Practice Recommendations in the Performance Assessment Literature and Investigation of Current Practices in Predoctoral Dental Education". Journal of Dental Education. Vol.72, Num. 12, pp.1405-1431.

10. David W. Chambers Ed.M., M.B.A., PhD. "Towards a competency based curriculum" Journal of Dental Education. Vol.57, Num. 11, pp.790-793.

11. David W. Chambers Ed.M., M.B.A., PhD. "A primer on competency based evaluation" Journal of Dental Education. Vol.62, Num. 8, pp.651-666.

Bangladesh Journal of Medical Education 2017;8(2):24-28. 